Supplemental Information for:

\title{
Structural Assessment and Catalytic Consequences of the Oxygen Coordination Environment in Grafted Ti-Calixarenes
}

Justin M. Notestein, Leandro R. Andrini, Vitali I. Kalchenko, Felix G. Requejo, Alexander Katz, and Enrique Iglesia

\section{Manuscript JA065830C}

Characterization data for compound $\mathbf{4 a}$ :

${ }^{1} \mathrm{H}$ NMR: (400 MHz, $\left.\mathrm{CDCl}_{3}, 298 \mathrm{~K}\right), \delta 1.23$ (s, 9H, tBu), 1.19 (s, 9H, tBu), 1.27 (s, 18H, $\mathrm{tBu}), 3.26\left(\mathrm{~d}, 4 \mathrm{H},{ }^{3} \mathrm{~J}=11.6 \mathrm{~Hz}\right.$, exo- $\left.\mathrm{CH}_{2}\right), 3.71\left(\mathrm{~s}, 3 \mathrm{H}, \mathrm{OCH}_{3}\right), 4.22\left(\mathrm{~d}, 2 \mathrm{H},{ }^{3} \mathrm{~J}=12.4 \mathrm{~Hz}\right.$, endo$\left.\mathrm{CH}_{2}\right), 4.63\left(\mathrm{~d}, 2 \mathrm{H},{ }^{3} \mathrm{~J}=12.4 \mathrm{~Hz}\right.$, endo- $\left.\mathrm{CH}_{2}\right), 7.0-7.4(\mathrm{~m}, 17 \mathrm{H}, \mathrm{ArH}), 7.90\left(\mathrm{dd}, 6 \mathrm{H},{ }^{3} \mathrm{~J}=1.6 \mathrm{~Hz},{ }^{3} J\right.$ $=8 \mathrm{~Hz})$ o- $\mathrm{SiPh}_{3} .{ }^{13} \mathrm{C} \mathrm{NMR}:\left(400 \mathrm{MHz}, \mathrm{CDCl}_{3}, 298 \mathrm{~K}\right): \delta 31.11\left(\mathrm{C}(\underline{\mathrm{CH}})_{3}\right), 31.38\left(\mathrm{C}\left(\underline{\mathrm{CH}}_{3}\right)_{3}\right)$, $31.44\left(-\mathrm{CH}_{2}-\right), 31.57\left(-\mathrm{CH}_{2}^{-}\right), 31.63\left(\mathrm{C}\left(\underline{\mathrm{CH}}_{3}\right)_{3}\right), 33.29\left(-\mathrm{CH}_{2}-\right), 33.49\left(-\mathrm{CH}_{2}-\right), 34.12\left(\underline{\mathrm{C}}\left(\mathrm{CH}_{3}\right)_{3}\right)$, $65.49\left(\mathrm{OCH}_{3}\right), 123.63$ (Ar), 124.88 (Ar), 125.11 (Ar), 127.03(Ar), 127.68 (Ar), 127.84 (Ar), 128.15 (quat, Ar), 129.50 (Ar), 129.83 (Ar), 129.99 ( $\alpha$-SiAr), 132.32 ( $\alpha$-SiAr), 134.88 (SiAr), 135.24 (SiAr), 144.25, ( $\alpha$-OAr), 148.27 ( $\alpha$-OAr), 160.15 ( $\alpha$-OAr). Methylenes and quaternary carbons were identified by the DEPT 135 pulse sequence. Calixarene and. triphenylsilanol Ar carbons were identified by a ${ }^{1} \mathrm{H}_{-}{ }^{13} \mathrm{C}$ HMBC pulse sequence.

${ }^{29}$ Si NMR: (400 MHz, $\left.\mathrm{CDCl}_{3}, 298 \mathrm{~K}\right)$ : $-15.9 \mathrm{ppm}$ vs tetramethylsilane internal standard. ${ }^{29} \mathrm{Si}$ resonances were observed indirectly using a ${ }^{1} \mathrm{H}-{ }^{29} \mathrm{Si} H \mathrm{HBC}$ experiment. Triphenylsilanol possess a ${ }^{29} \mathrm{Si}$ resonance at $-12.5 \mathrm{ppm}$ and an $\mathrm{o}-\mathrm{SiPh}_{3}{ }^{1} \mathrm{H}$ resonance at $7.55 \mathrm{ppm}(\mathrm{dd})$. A condensation product formed by direct addition of 1 eq $\mathrm{TiOPr}_{4}$ to 4 eq $\mathrm{Ph}_{3} \mathrm{SiOH}$, which can arise as a side product in this reaction possess a ${ }^{29} \mathrm{Si}$ resonance at $-14.6 \mathrm{ppm}$ and an $\mathrm{o}-\mathrm{SiPh}_{3}{ }^{1} \mathrm{H}$ resonance at $7.31 \mathrm{ppm}(\mathrm{dd}) . \mathrm{Ti}\left(\mathrm{OSiPh}_{3}\right)_{4}$, which appears to form as a minor product by this synthesis procedure, possesses an $\mathrm{o}-\mathrm{SiPh}_{3}{ }^{1} \mathrm{H}$ resonance at $7.63 \mathrm{ppm}(\mathrm{dd})$, which matches the literature. (Johnson et al., J. Orgamomet. Chem. 2000, 596, 221)

The downfield shifts in the ${ }^{1} \mathrm{H}$ NMR spectrum of the o- $\mathrm{SiPh}_{3}$ protons relative to free triphenylsilanol, the disappearance of a resonance for the $\mathrm{SiOH}$ group, and the shift in the ${ }^{29} \mathrm{Si}$ 
resonance relative to that of free triphenylsilanol $(-12.5 \mathrm{ppm})$ are indicative of complex formation between $\mathrm{Ti}$ and triphenylsilanol. No resonances corresponding to free or bound $\mathrm{HO}^{\mathrm{i}} \mathrm{Pr}$ were found. The disappearance of a resonance for the calixarene phenol protons and the downfield ${ }^{13} \mathrm{C}$ NMR shift of the $\alpha$-OAr carbons relative to that of free calixarene indicate complex formation between $\mathrm{Ti}$ and calixarene.

FAB MS (NPOE matrix) calculated: $982.5 \mathrm{~m} / \mathrm{z}$, measured: $\mathrm{M}^{+} 982.5 \mathrm{~m} / \mathrm{z}$. Elemental analysis calculated: C 76.96, H 7.18, Ti 4.87; measured: C 76.31, H 7.40, Ti 4.64.

Presumed Intermediate

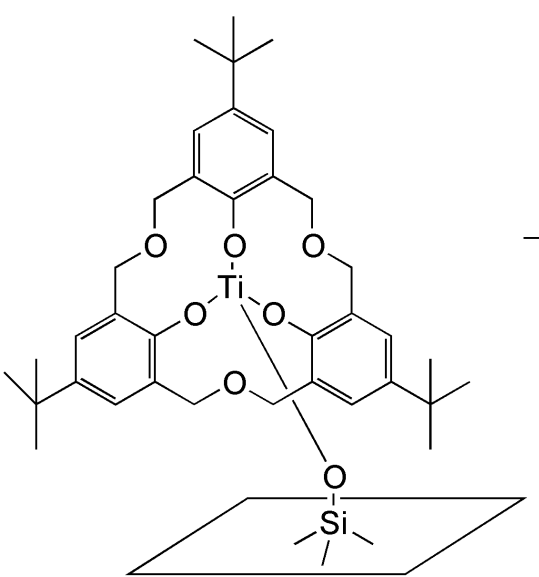

Presumed Structure of $3 \mathrm{c}$

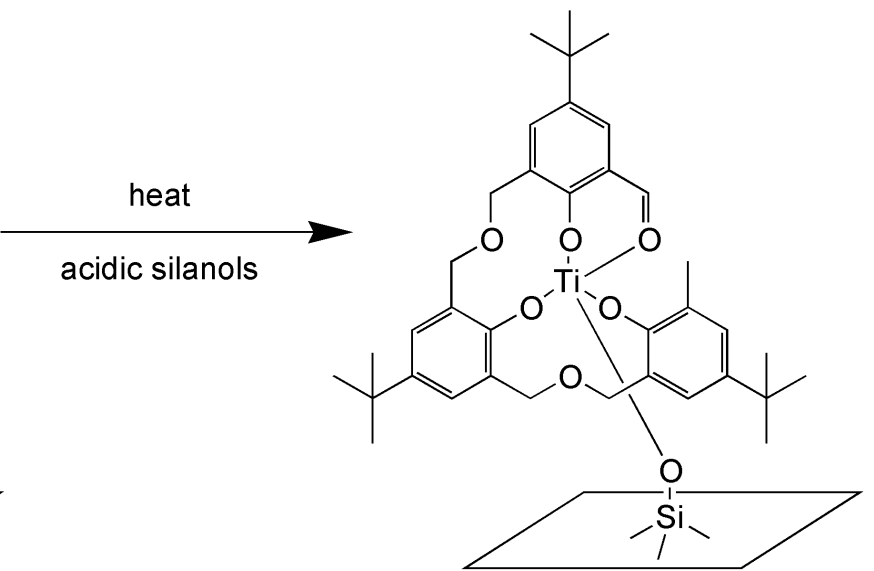

Scheme S1. Alternate perspectives for possible structures of material 3c, accounting for the higher coordination relative to material 3a and the observation of carbonyl resonances. 


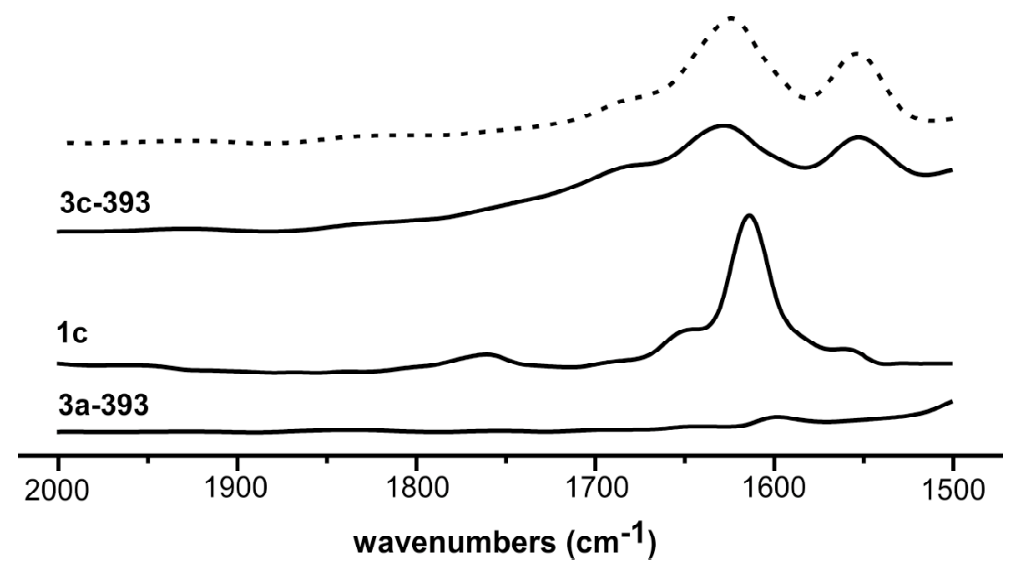

Figure S1. Transmission mode FTIR of materials 3a and $\mathbf{3 c}$ after pretreatment at 393 K, with the $\mathrm{SiO}_{2}$ background numerically removed by scaling for the silica overtone at $1880 \mathrm{~cm}^{-1}$. Pure ligand homooxacalix[3]arene 1c, is also included. The latter spectrum was independent of treatment temperature below $393 \mathrm{~K}$, as expected for a homogeneous organic species. Within the range 1500-2000 cm-1, 3a has no discernable peaks, and $\mathbf{1 c}$ has a prominent peak at $1610 \mathrm{~cm}^{-1}$. In contrast, material 3a as synthesized (-) and after exposure to tert-butyl hydroperoxide under epoxidation conditions (but in the absence of alkene), washing, drying, and a second treatment at $393 \mathrm{~K}$ in dynamic vacuum (- - ) have strong peaks at $1680 \mathrm{~cm}^{-1}, 1640 \mathrm{~cm}^{-1}$, and $1560 \mathrm{~cm}^{-1}$, all indicative of carbonyl species. After exposure to hydroperoxide, the peak at $1640 \mathrm{~cm}^{-1}$ increases in relative intensity. The prevalence of this species under reaction conditions may account for the change in carbonyl intensity observed in solid-state ${ }^{13} \mathrm{C}$ NMR after reaction. 


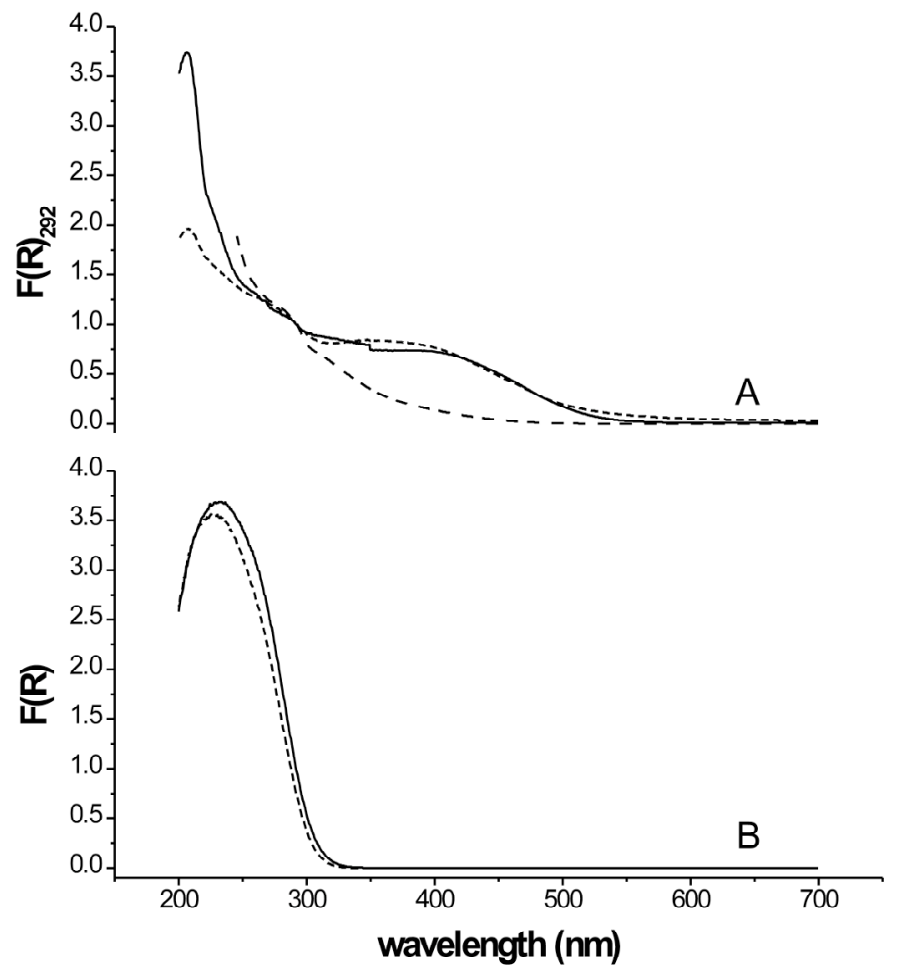

Figure S2. (A) Diffuse reflectance UV-visible spectra of 3a $(-), \mathbf{3 c}(--)$, and solution spectrum of 4a (- - -). Absorption intensities are expressed as absorbance (4a) or F(R) (pseudoabsorbance, 3a, 3c) relative to value at $292 \mathrm{~nm}$, the absorption maximum for free calixarene ligand. (B) Diffuse reflectance UV-visible spectra of 3a-823 (-), 3c-823 (- —). The absence of any absorption beyond $300 \mathrm{~nm}$ indicates well dispersed $\mathrm{Ti}$ on $\mathrm{SiO}_{2}$. 

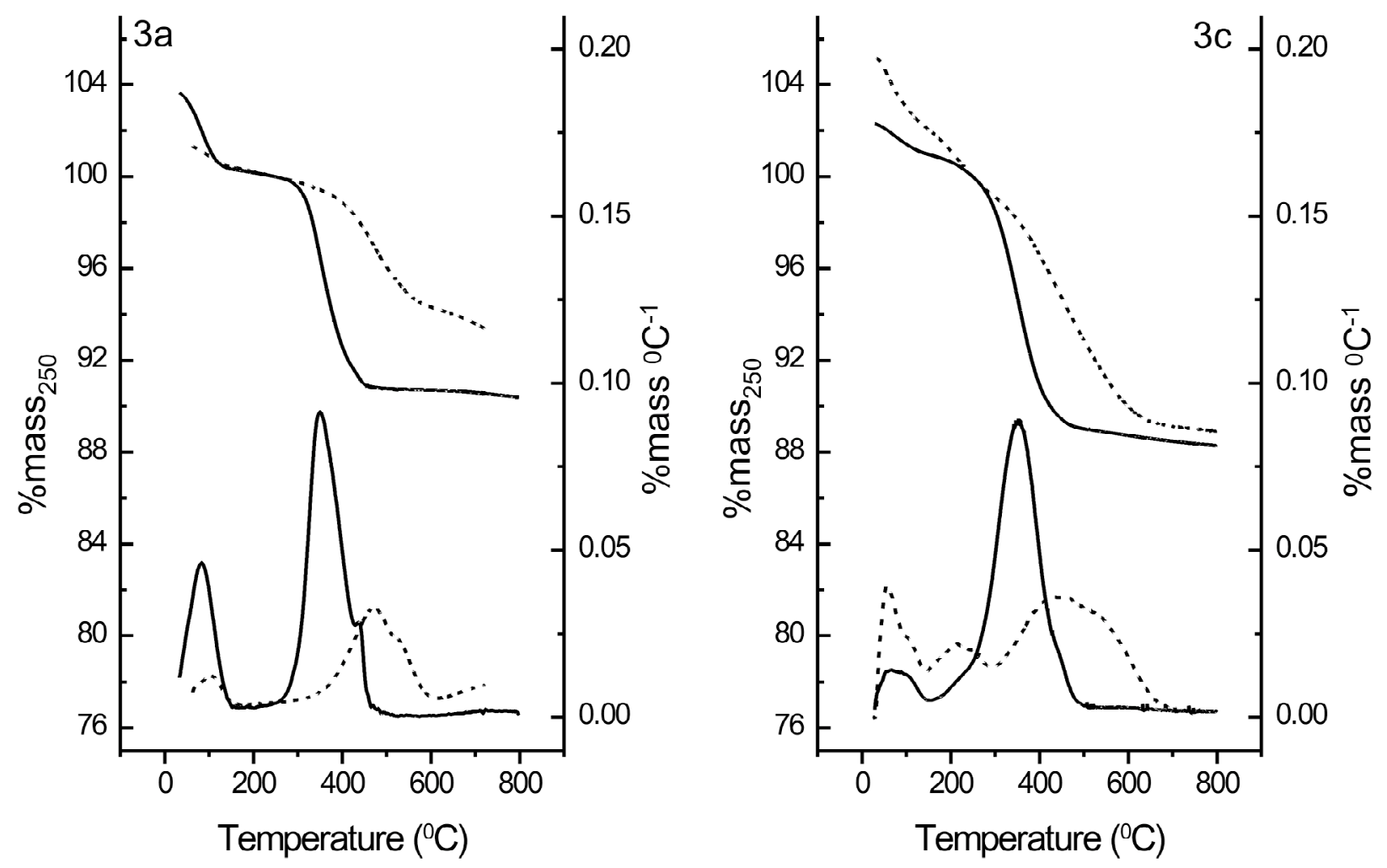

Figure S3. Mass relative to mass at $250^{\circ} \mathrm{C}$ and rate of mass loss per degree $\mathrm{C}$ for calixarene-Ti materials 3a and 3c in $\mathrm{N}_{2} / \mathrm{O}_{2}(-)$ and $\mathrm{N}_{2}(---)$. Note that the onset of primary mass loss for material 3c in $\mathrm{N}_{2}$ becomes occurs at $\sim 300^{\circ} \mathrm{C}$. 